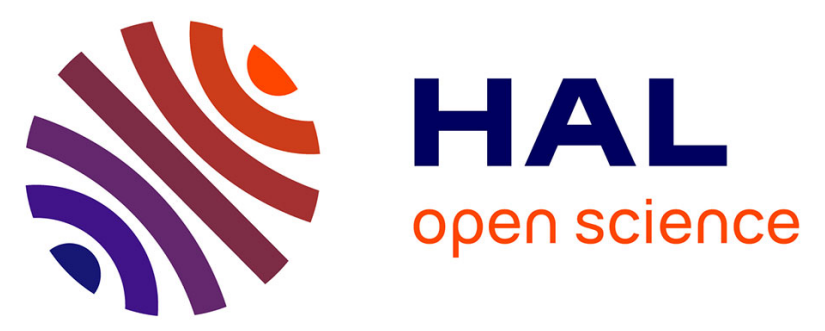

\title{
Layer-by-Layer Assembly of Nanosized Membrane Fractions for the Assessment of Cytochrome P450 Xenobiotic Metabolism
}

Paul Quantin, Elodie Colaço, Karim El Kirat, Christophe Egles, Hervé Ficheux, Jessem Landoulsi

\section{To cite this version:}

Paul Quantin, Elodie Colaço, Karim El Kirat, Christophe Egles, Hervé Ficheux, et al.. Layer-byLayer Assembly of Nanosized Membrane Fractions for the Assessment of Cytochrome P450 Xenobiotic Metabolism. ACS Omega, 2018, 3 (10), pp.12535 - 12544. 10.1021/acsomega.8b01738 . hal01934732

\section{HAL Id: hal-01934732 https://hal.sorbonne-universite.fr/hal-01934732}

Submitted on 26 Nov 2018

HAL is a multi-disciplinary open access archive for the deposit and dissemination of scientific research documents, whether they are published or not. The documents may come from teaching and research institutions in France or abroad, or from public or private research centers.
L'archive ouverte pluridisciplinaire HAL, est destinée au dépôt et à la diffusion de documents scientifiques de niveau recherche, publiés ou non, émanant des établissements d'enseignement et de recherche français ou étrangers, des laboratoires publics ou privés.

\section{(c)(1)}

Distributed under a Creative Commons Attribution| 4.0 International License 


\title{
Layer-by-Layer Assembly of Nanosized Membrane Fractions for the Assessment of Cytochrome P450 Xenobiotic Metabolism
}

\author{
Paul Quantin, ${ }^{\dagger, \grave{ }}$ Elodie Colaço, ${ }^{\ddagger}$ Karim El Kirat, ${ }^{\ddagger}$ Christophe Egles, ${ }^{\ddagger}$ Hervé Ficheux,
} and Jessem Landoulsi* ${ }^{*}, \$, \$ \odot$

\author{
${ }^{\dagger}$ Département de Toxicologie, THOR Personal Care, 147 Rue Irene Joliot Curie, 60610 La Croix-Saint-Ouen, France \\ ${ }^{\ddagger}$ Université de Technologie de Compiègne, Laboratoire de Biomécanique \& Bioingénierie, CNRS, UMR 7338, Rue Personne de \\ Roberval, 60200 Compiègne, France \\ ${ }^{\S}$ Sorbonne Université, CNRS - UMR 7197, Laboratoire de Réactivité de Surface, 4 Place Jussieu, F-75005 Paris, France
}

\section{Supporting Information}

\begin{abstract}
Herein, we report the use of sequential layerby-layer (LbL) assembly to design nanostructured films made of recombinant bacterial membrane fractions (MF), which overexpress cytochrome P450 (CYP) and cytochrome P450 reductase. The ability to incorporate $\mathrm{MF}$ in $\mathrm{LbL}$ multilayered films is demonstrated by an in situ quartz crystal microbalance with dissipation monitoring using poly-L-lysine or poly-Lornithine as a polycation. Results show that MF preserve a remarkable CYP1A2 catalytic property in the adsorbed phase. Moreover, atomic force microscopy images reveal that MF mostly adopt a flattened conformation in the adsorbed phase with an extensive tendency to aggregate within the multilayered films, which is more pronounced when increasing the number of bilayers. Interestingly, this behavior seems to enhance the ability of embedded MF to remain active after repeated uses. The proposed strategy constitutes a practical alternative for the immobilization of active CYP enzymes. Besides their fundamental interest, MF-based multilayers are useful nano-objects for the creation of new biomimetic reactors for the assessment of xenobiotic metabolism.
\end{abstract}

\section{INTRODUCTION}

Human organisms are more and more extensively exposed to various xenobiotics, such as cosmetics, drugs, and pollutants. ${ }^{1}$ These substances may indeed interact with the body and be potentially absorbed by three different routes: respiratory, oral, and cutaneous. Accordingly, the evaluation of the potential toxic effects due to absorbed xenobiotics is highly desired. Over the last decades, animals have been used as models to investigate and predict the impact of chemical substances on living human organisms. ${ }^{2,3}$ However, animal experimentation is more and more subjected to many restrictions due to ethical considerations. ${ }^{4}$ Moreover, toxicological tests performed on animal models are difficult to extrapolate to human physiology so that their relevance is increasingly questionable. ${ }^{5}$ In Europe, the regulatory environment for cosmetic products requires the use of alternative approaches to assess their safety. ${ }^{6}$ In the other chemical industries, regulations are less stringent but strong ethical pressure has resulted in the application of the $3 \mathrm{R}$ rules for animal testing: reduce, refine, and replace animal models. ${ }^{7}$

In toxicological assessment, one of the main issues is related to the biotransformation of the absorbed chemical substances to metabolites that may exhibit high reactivity. Xenobiotic metabolism is found in different tissues, ${ }^{8}$ including skin, lungs, kidneys, and liver.

The development of biomimetic predicting systems that incorporate xenobiotic metabolisms has been reported in previous studies.' They are generally focused on the use of cytochrome P450 (CYP) metabolism, which is considered as the major pathway for xenobiotic's biotransformation. CYP is a family of heme-containing mono-oxygenase enzymes, which catalyze the hydroxylation; epoxidation; and N-, S-, and Odemethylation of a substrate according to (eq 1)

$$
\begin{gathered}
\mathrm{R}-\mathrm{H}+\mathrm{O}_{2}+\mathrm{NADPH}+\mathrm{H}^{+} \\
\rightarrow \mathrm{R}-\mathrm{OH}+\mathrm{H}_{2} \mathrm{O}+\mathrm{NADP}^{+}
\end{gathered}
$$

In vivo, the CYP-catalyzed reaction requires two electrons, provided by cytochrome $\mathrm{P} 450$ reductase (CPR) and cytochrome b5 (Cyt b5), and uses the nicotinamide adenine dinucleotide phosphate (NADPH) cofactor as a reducing agent. $^{10-12}$ In eukaryotic cells, CYP, CPR, and Cyt b5 are located in the intracellular space in the smooth endoplasmic

Received: July 21, 2018

Accepted: September 19, 2018

Published: October 3, 2018 
reticulum membranes and include a hydrophobic transmembrane binding domain. ${ }^{13,14}$ The immobilization of CYP and the preservation (here it is in the sense of maintaining/ conserving the activity) of its activity is thus a challenge, owing to the complexity of the electron pathway. Many papers have reported different strategies for the immobilization of purified CYP on electrodes. ${ }^{15}$ This way of immobilizing CYP eliminated the need for $\mathrm{NADPH}$ and $\mathrm{CPR}$, and the enzyme can accept electrons directly from the electrode. Another promising alternative consists in the use of microsomal fractions in which CYP is expressed with its reductases. These fractions may be obtained from cell centrifugation to isolate endoplasmic reticulum membranes expressing CYP. In a previous study, microsomes, extracted from rat liver, were immobilized on an amino silane-modified surface, revealing promising catalytic properties. ${ }^{21}$ However, the extraction of these microsomes is particularly difficult and their relevancy to toxicological tests is poor for the reasons detailed above. Furthermore, the procedure of immobilization presents a significant weakness owing to the quality of silane layers on inorganic supports and their low stability in aqueous media of biological interest. ${ }^{16-19}$ An alternative way to coexpress human CYP and CPR in microsomal fractions has been proposed by Blake et al. $^{20}$ and more recently by Quehl et al. ${ }^{21}$ The procedure consists in targeting the expression of a human CYP and CPR in bacterial membrane fractions (MF) from Escherichia coli by genetic engineering techniques. Interestingly, the recombinant CYP produced by this method yields active enzymes toward a variety of substrates in the absence of Cyt b5. ${ }^{22,23}$

The aim of this study is to develop an efficient and straightforward method to immobilize microsome-like structures containing human CYP coexpressed with $\mathrm{CPR}$ and to preserve their catalytic properties for the assessment of xenobiotic's metabolism. For this purpose, we used layer-bylayer ( $\mathrm{LbL}$ ) sequential assembly, which is a versatile technique for the elaboration of nanostructured films with tailored properties and functions. This technique was originally based on the alternating adsorption of oppositely charged polymers, polyelectrolytes, on a charged substrate. ${ }^{24,25}$ Electrostatic interactions have been thoroughly investigated for the construction of polyelectrolyte multilayers. ${ }^{26,27}$ Other interactions, including hydrogen bonding, hydrophobic interaction, and van der Waals forces, have been also studied. ${ }^{28-30}$ Importantly, the LbL assembly has allowed a variety of molecules of biological interests to be incorporated while preserving their structure and bioactivity. ${ }^{31,32}$ In particular, many studies have reported the immobilization of purified enzymes, and other active proteins, through LbL assembly to design specific bioreactors and biosensors. These include glucose oxidase, ${ }^{33,34}$ catalase, ${ }^{35}$ myoglobin, ${ }^{36}$ etc. In another study, the LbL assembly of alkaline phosphatase embedded in phospholipid vesicles was explored as a reactor for mineralization. ${ }^{37}$ The authors observed the formation of calcium phosphate mineral within the multilayered film. Recently, enzyme-polyelectrolyte complexes have been incorporated in multilayered films showing a remarkable improvement of the catalytic properties. ${ }^{38}$ All of these studies, and others reported in the literature, clearly show the interest of using the LbL technique for the immobilization of active biocompounds while preserving (maintaining/ conserving), or even improving, their catalytic properties. In the present study, the possibility to incorporate recombinant bacterial membrane fractions in a multilayered film, designed through the LbL assembly, is investigated and their catalytic activities and operation stability are evaluated.

\section{RESULTS AND DISCUSSION}

2.1. Characteristics of MF. MF were prepared from the cell wall of E. coli as described in the Experimental Section. The composition of MF was determined by infrared spectroscopy, a technique broadly used for the characterization of biointerfaces. ${ }^{39}$ Figure 1 shows a typical attenuated total

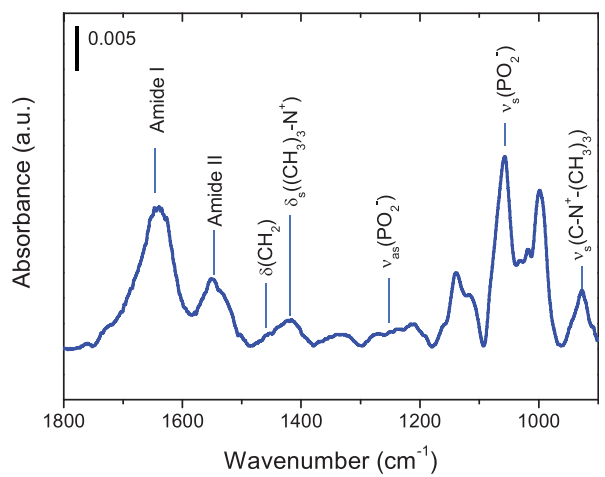

Figure 1. Representative ATR-IR spectrum recorded on a MF solution (20 nM, PBS) at room temperature.

reflection infrared (ATR-IR) spectrum recorded on a solution of MF (20 nM, phosphate buffer saline (PBS)). The bands at 1647 and $1557 \mathrm{~cm}^{-1}$ may be assigned to amide I and II bands, respectively, characteristic of the peptide bonds found in proteins. The band at $1460 \mathrm{~cm}^{-1}$ can be attributed to the methylene scissoring mode $\delta\left(\mathrm{CH}_{2}\right)$. Typical bands due to chemical functions present in phospholipids were also observed. The broadening near $1730 \mathrm{~cm}^{-1}$ may be attributed to $\nu(\mathrm{C}=\mathrm{O})$ in the ester group of the acyl-glycerol backbone. The symmetric bending $\left(\delta_{\mathrm{s}}\right)$ mode of the methyl groups attached to the nitrogen atom in the choline moiety $\left(\mathrm{CH}_{3}\right)_{3}-$ $\mathrm{N}^{+}$) appeared at $1416 \mathrm{~cm}^{-1}$, but their asymmetric vibrational mode, at around $1480 \mathrm{~cm}^{-1}$, was not clearly observed. The characteristic band due to symmetric and asymmetric stretching modes of phosphate groups, $\nu_{s}\left(\mathrm{PO}_{2}^{-}\right)$and $\nu_{\text {as }}\left(\mathrm{PO}_{2}^{-}\right)$, appeared at 1057 and $1250 \mathrm{~cm}^{-1}$, respectively. It appears that polysaccharides are not present in a significant amount, but their presence could not be completely ruled out. Indeed, this would give bands due to the stretching of $\mathrm{C}-\mathrm{O}$ and $\mathrm{C}-\mathrm{O}-\mathrm{C}$ groups in the $1050-1085 \mathrm{~cm}^{-1}$ region, ${ }^{40,41}$ which are overlapping with the intensive $\nu_{\mathrm{s}}\left(\mathrm{PO}_{2}^{-}\right)$band. It is worth reminding that the cell wall of E. coli is composed of (i) an inner membrane (lipid bilayer), (ii) peptidoglycans, and (iii) an outer membrane that also includes lipopolysaccharides. $^{42,43}$ As CYP and CPR are overexpressed in the inner membrane, the procedure used for the preparation of MF includes an enzymatic digestion of the outer membrane. This allows the removal of polysaccharides and peptidoglycans to avoid diffusion constraints toward catalytic activities of enzymes, leading to the formation of spheroplast. ${ }^{44}$ This is in accordance with ATR-IR data (Figure 1) showing that MF mainly consists of proteins, including the overexpressed enzymes, and phospholipids originating from bacterial cell wall.

The stability of MF and their behavior in PBS were investigated by means of dynamic light scattering (DLS) and electrophoretic mobility (EPM) measurements. The mobility 
Table 1. Main Characteristics of Membrane Fractions (MF)

\begin{tabular}{|c|c|c|c|c|c|}
\hline & \multirow[b]{2}{*}{ hydrodynamic diameter $(\mathrm{nm})^{a}$} & \multirow[b]{2}{*}{ electrophoretic mobility $\left(\mathrm{m}^{2} \mathrm{~V}^{-1} \mathrm{~s}^{-1} \times 10^{-8}\right)$} & \multirow[b]{2}{*}{$\zeta$ potential $(\mathrm{mV})$} & \multicolumn{2}{|c|}{ height $(\mathrm{nm})^{b}$} \\
\hline & & & & low coverage & high coverage \\
\hline mean $\pm S D$ & $219 \pm 64.1$ & $-3.91 \pm 0.11$ & $-52.9 \pm 1.45$ & $32.4 \pm 28.5$ & $49.5 \pm 27.7$ \\
\hline
\end{tabular}

of MF in PBS solution was $-3.91 \pm 0.11 \mathrm{~m}^{2} \mathrm{~V}^{-1} \mathrm{~s}^{-1} \times 10^{8}$, as determined by EPM measurements, yielding the $\zeta$ potential value of $-52.9 \pm 1.45 \mathrm{mV}$, considering $\mathrm{MF}$ as spheroid-shaped particles (Table 1). This suggests that MF exhibit an overall negatively charged surface in PBS. According to the literature, the inner lipid bilayer of E. coli (used for the elaboration of MF used in this study) typically includes about $75 \%$ of zwitterion (phosphatidylethanolamines) and about $20 \%$ of anionic lipids (phosphatidylglycerols and cardiolipin). ${ }^{42,43}$

Typical DLS profiles are presented in Figure 2A at different concentrations of MF. Results revealed a large particle size distribution with a mean value around $200 \mathrm{~nm}$. The polydispersity index, which provides a direct information regarding the particle size distribution, was around $0.165 \mathrm{~nm}$. This trend was independent of the concentration of MF solutions. Furthermore, time-resolved DLS monitoring showed that the hydrodynamic diameter of MF did not vary with time, showing values around $200 \mathrm{~nm}$ (Figure 2B).

Additional indications regarding the morphology of MF may be obtained by AFM imaging. For this purpose, a glass slide was used as a substrate for the adsorption of MF. After stabilization in the liquid phase (PBS), a solution of MF (20 $\mathrm{nM}$ ) was injected in the AFM liquid cell. Representative images recorded at the early stage $(\sim 5 \mathrm{~min})$ and after about 30 min (and more) of MF adsorption are given in Figure 3. Results showed the presence of isolated particles randomly distributed on the surface (Figure 3A). Typical cross sections revealed that the heights of these particles may vary from values around $10 \mathrm{~nm}$ to values exceeding $50 \mathrm{~nm}\left(R_{\mathrm{rms}}=6.9\right.$ $\mathrm{nm}$, Figure $3 \mathrm{~B}$ ), yielding a large height distribution (Figure 3C). After about $30 \mathrm{~min}$ of adsorption, the AFM image showed a noticeable increase of the particle size and surface coverage (Figure 3D). The height distribution indicated a higher polydispersity of particle size (Figure 3E,F) compared to that observed after $5 \mathrm{~min}$ of adsorption, and the surface roughness increased markedly $\left(R_{\mathrm{rms}}=11.1 \mathrm{~nm}\right)$.

The characteristics of MF obtained with the different techniques detailed above are summarized in Table 1 . It is shown that the dimensions of MF varied noticeably whether it is determined in the bulk (DLS) or on a solid surface (AFM). It must be kept in mind that the techniques used provide two different measurements: while DLS measures a hydrodynamic diameter of free particles in solution, including a hydration shell, AFM measures the height of particles deposited on a solid surface. Owing to their softness, adsorbed MF may be deformed by the AFM tip under imaging. By using peak force tapping mode, the applied force is lower than that in the classical tapping mode (applied force $\sim 400 \mathrm{pN}$ ) and allows probing the interface with minimal disturbance. The difference is thus too large to be explained by the above considerations. The disparity between DLS and AFM measurements may originate from the conformation MF adopt in the adsorbed state. Results suggest that MF are flattened once adsorbed on a solid surface. The adsorption-induced deformation is, indeed, with a common occurrence for spheroid-shaped lipid bilayer particles (liposomes) and depends on many factors such as the
A
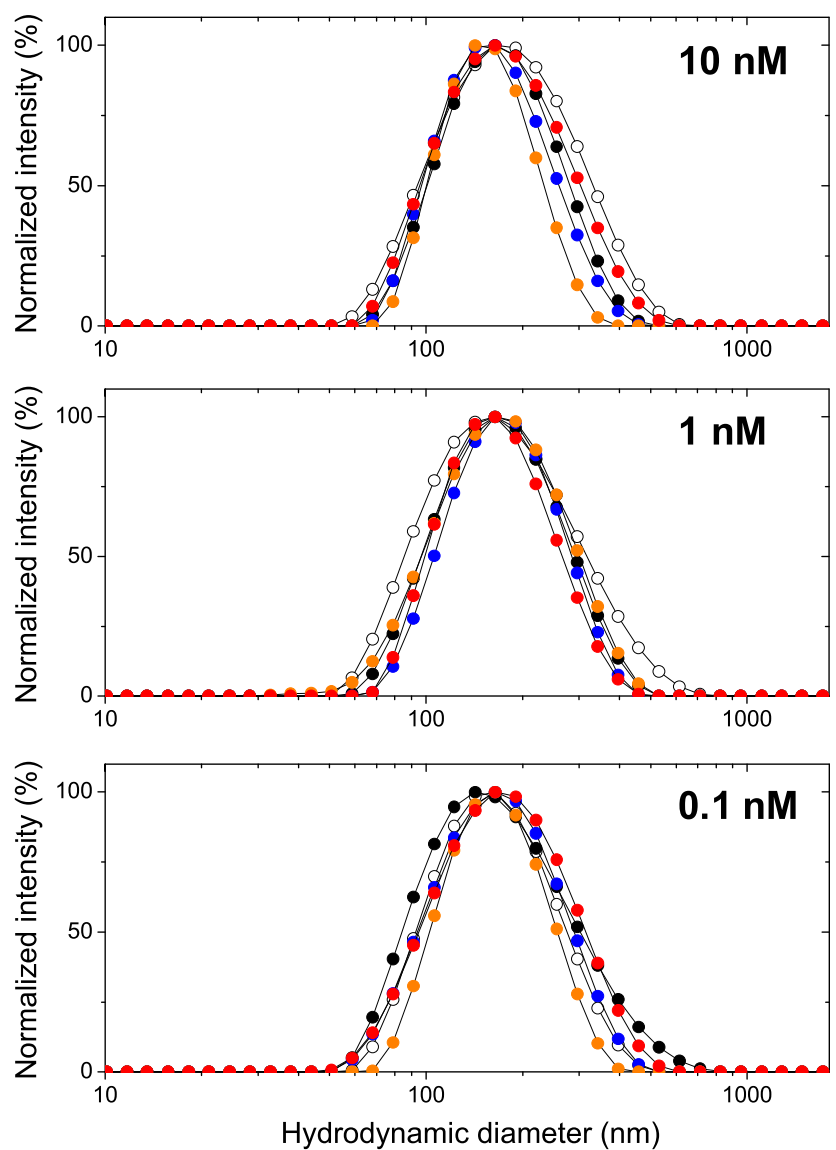

B

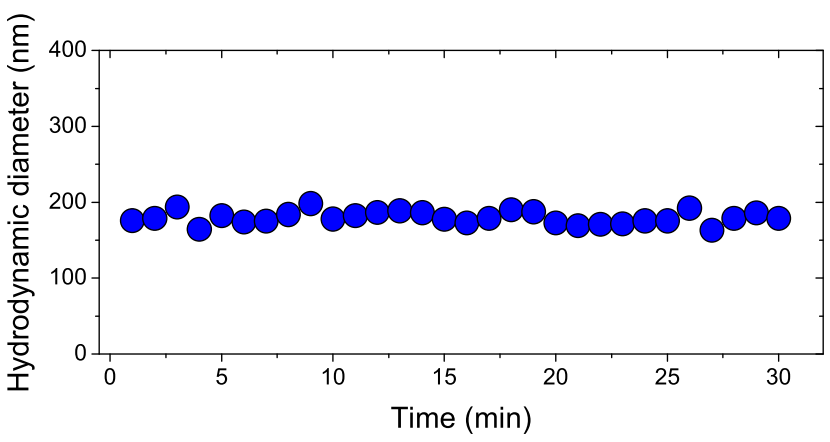

Figure 2. (A) Representative particle size distributions (five runs are presented in each graph) obtained by DLS of MF solutions at different concentrations $(10,1,0.1 \mathrm{nM} ; \mathrm{PBS})$ at room temperature. (B) Typical real-time DLS profile of MF solution (10 nM, PBS).

osmotic pressure difference over the liposomal bilayer, the strength of liposome-surface interaction, etc. ${ }^{45-48}$ To scrutinize the adsorption behavior of MF on the studied surface, in situ quartz crystal microbalance with dissipation (QCM-D) monitoring was performed on a $\mathrm{SiO}_{2}$-coated 

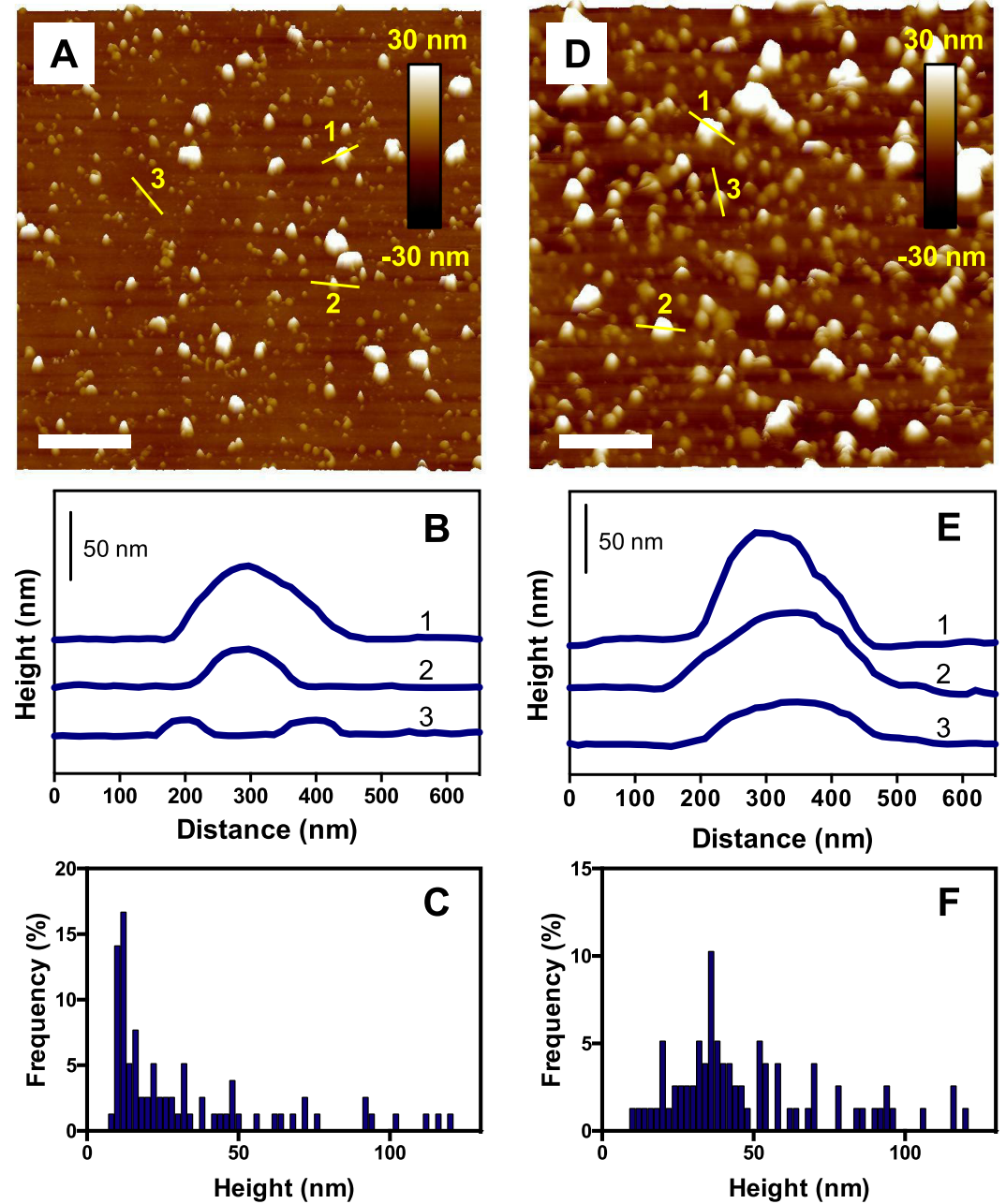

Figure 3. Morphology of MF in the adsorbed phase. Representative AFM height images recorded in PBS buffer solution on glass slides after injection of MF solution in the AFM liquid cell. Images were recorded after MF adsorption for about 5 min (A) or about 30 min (D). (B, E) Cross sections taken at the locations indicated by the straight lines and numbered in images (A) and (D), respectively. (C, F) Histograms of the aggregate heights $(n=78)$ corresponding to images (A) and (D), respectively (scale bars $=1 \mu \mathrm{m})$.

substrate (Figure 4). The latter technique is a powerful tool to study the formation of a hydrated thin film on solid surfaces. ${ }^{49}$ In aqueous solutions, this technique monitors changes in resonance frequency, $\Delta f$, and dissipation of a coated quartz crystal due to the adsorption of a hydrated mass. This also provides information regarding the viscoelastic properties of the adsorbed phase. ${ }^{50}$ Results showed strong shifts in resonance frequency, $\Delta f_{n} / n$, and dissipation as a function of time for the different overtones $(n=1-13)$ due to the adsorption of $\mathrm{MF}$ on the $\mathrm{SiO}_{2}$-coated surface. The high dissipation values and the strong dependence of the frequency shifts on the number of overtones indicate the formation of a soft and highly hydrated layer. Upon rinsing in buffer, MF remained completely adsorbed on the substrate. The frequency shifts vs time did not show typical profiles of vesicle rupture, ${ }^{51}$ suggesting the adsorption of "intact" MF. The adsorption of vesicles without rupture remains less understood ${ }^{52}$ compared to that with fusion, a process broadly used for the formation of a supported lipid bilayer. ${ }^{53,54}$ Moreover, these studies are generally conduced with monodisperse liposomes, whereas MF are highly polydisperse (cf. DLS data, Figure 2). Larger MF are subjected to more extensive deformation in the adsorbed state, but this behavior is difficult to detect by QCM-D. ${ }^{52}$ At low surface coverage, i.e., when the hydrodynamic coupling between neighboring adsorbed particles can be neglected, QCM-D data may be used for probing the deformation of vesicles in the adsorbed state. ${ }^{48}$ This corresponds to short times after the injection of MF (linear frequency shifts, $t \sim 5$ min, Figure 4). In this case, the extraction of particle shape from QCM-D data (see the Supporting Information for more details, Figure S1) concerns small MF because the adsorption rate is limited by the diffusion of MF in the bulk so that larger MF diffuse more slowly. Results showed that the aspect ratio of MF initially adsorbed on the surface is close to 1 (Figure S1, Supporting Information). This suggests that only MF with low hydrodynamic diameter (typically $<40 \mathrm{~nm}$ ) did not deform in the adsorbed state at an early stage. By contrast, larger MF, more visible after $30 \mathrm{~min}$ of adsorption (Figure 3D), clearly adopted a flattened conformation at the solid surface, which seems to enhance their aggregation. This behavior did not lead, however, to a total surface coverage as it can be observed on the AFM height image (Figure 3D) and the Young modulus maps (Figure S2, Supporting Information)

2.2. Catalytic Activity in Solution. The catalytic properties of MF were first investigated in the buffer solution by means of the ethoxyresorufin O-deethylase (EROD) method, as described above. The activity was measured at 37 ${ }^{\circ} \mathrm{C}$ for different MF concentrations over a range of $0.1-16 \mathrm{nM}$ 

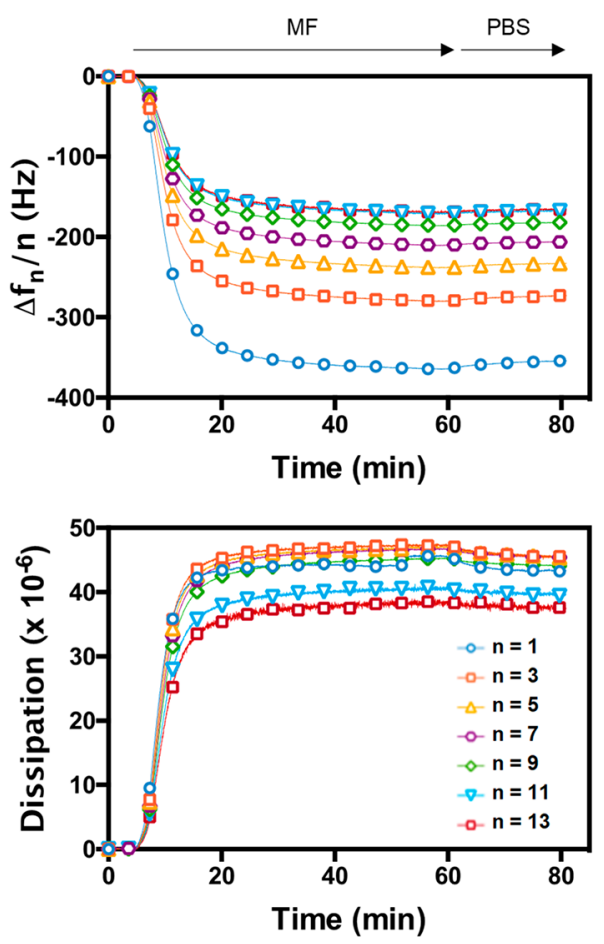

Figure 4. In situ monitoring of $\mathrm{MF}$ adsorption on $\mathrm{SiO}_{2}$ surface. Representative QCM-D measurements showing frequency changes in the fundamental $(n=1)$ and overtones $(n=3,5,7,9,11$, and 13) and the corresponding dissipation vs time during the adsorption of MF $(20 \mathrm{nM}, \mathrm{PBS})$ at room temperature.

of estimated CYP concentration. A typical evolution of the fluorescence vs time is given in Figure 5A. A calibration curve was preliminarily drawn to relate fluorescence to resorufin concentration (Figure 5A, inset). It is shown that the concentration of resorufin increased progressively as a result of the CYP-catalyzed reaction (eq 4), independently of the amount of MF introduced in the medium (Figure 5B). A fast increase was first observed corresponding to the initial activity of enzymes (linear portion of the curve). The slope of resorufin production decreased then as a function of time, indicating a decrease of the reaction kinetics (eq 4), to reach a plateau after about $30-40 \mathrm{~min}$. This trend is due to the mechanism of autoinactivation of enzymes. Different trends were observed for CYP from human liver microsomes or skin cell microsomes prepared from human primary keratinocytes (Figure S3, Supporting Information). For MF, the initial activity was determined by applying a linear fit and expressed as resorufin concentration produced per min. The metabolism ratesubstrate concentration relationship of MF used in the present study was satisfactorily consistent with the classical MichaelisMenten model (Figure S4, Supporting Information). The dependence of the catalytic activity on the enzyme concentration revealed a nonlinear relationship over the studied CYP concentration range (Figure 5C). However, at lower concentrations, a linear relationship was clearly observed (Figure 5C, inset), indicating that the substrate is in saturating amount in these conditions.

2.3. Layer-by-Layer Assembly. The sequential LbL assembly of (poly-L-lysine (PLL)/MF) ${ }_{n}$ and (poly-L-ornithine $(\mathrm{PLO}) / \mathrm{MF})_{n}$ multilayers on a flat substrate (where $n$ represents the number of adsorbed bilayers) was monitored in situ, in the hydrated state, using QCM-D. The polycation
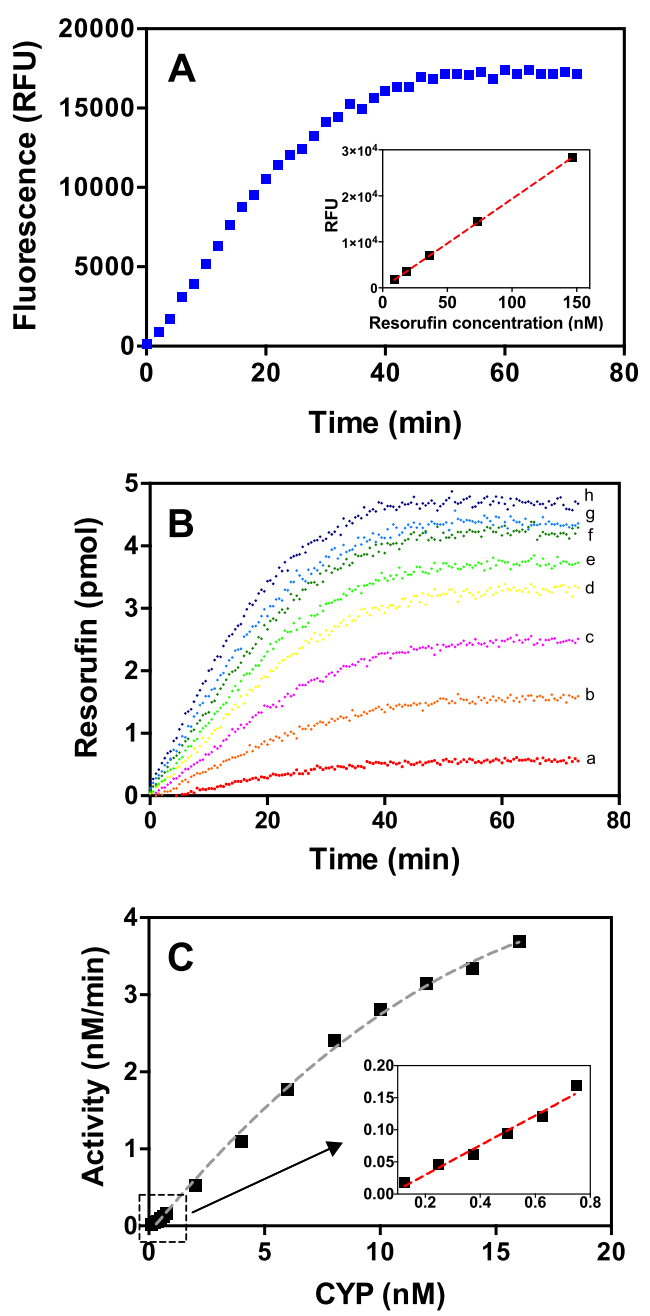

Figure 5. Measurements of CYP1A2 catalytic activity of MF using the EROD assay. (A) Evolution of the fluorescence $\left(\lambda_{\mathrm{ex}}=560 \mathrm{~nm}\right.$ and $\lambda_{\mathrm{em}}$ $=590 \mathrm{~nm}$ ) vs time due to the enzymatic production of resorufin (inset: calibration curve relating fluorescence to resorufin concentration). (B) Kinetics of resorufin formation over time at different CYP concentrations: $a=2 ; b=4 ; c=6 ; d=8 ; e=10 ; f=12 ; g=14$, and $h=16 \mathrm{nM}$. (C) Correlation between the catalytic activity (initial velocity) and the amount of CYP present in the solution (nM).

used was either PLL or PLO. These polyelectrolytes differ only slightly by their chemical functions (lysine vs ornithine), whereas their charge densities are similar. MF were incorporated as a polyanion because they exhibit an overall negatively charged surface in PBS based on EPM measurements (Table 1). The shifts of frequency and dissipation due to the alternated adsorption of PLL, or PLO, and MF were recorded (Figure 6A,B). The polycation was first adsorbed on the negatively charged surface of the $\mathrm{SiO}_{2}$-coated quartz crystal without any additional anchoring layer. A shift of the resonant frequency was recorded for each added layer corresponding to the adsorption of the polycation and MF. $\Delta f$ and dissipation due to the adsorption of MF were appreciably higher than those observed for PLL or PLO. The high dissipation observed after the adsorption of MF indicates that the added mass acts as a soft and viscoelastic adlayer. Dissipation values obtained with MF are appreciably higher compared to those with globular proteins ${ }^{16}$ or even other proteins forming meshworklike assemblies. ${ }^{55,56}$ The increase of dissipation was more pronounced with increasing the number of bilayers $n$. It is also 

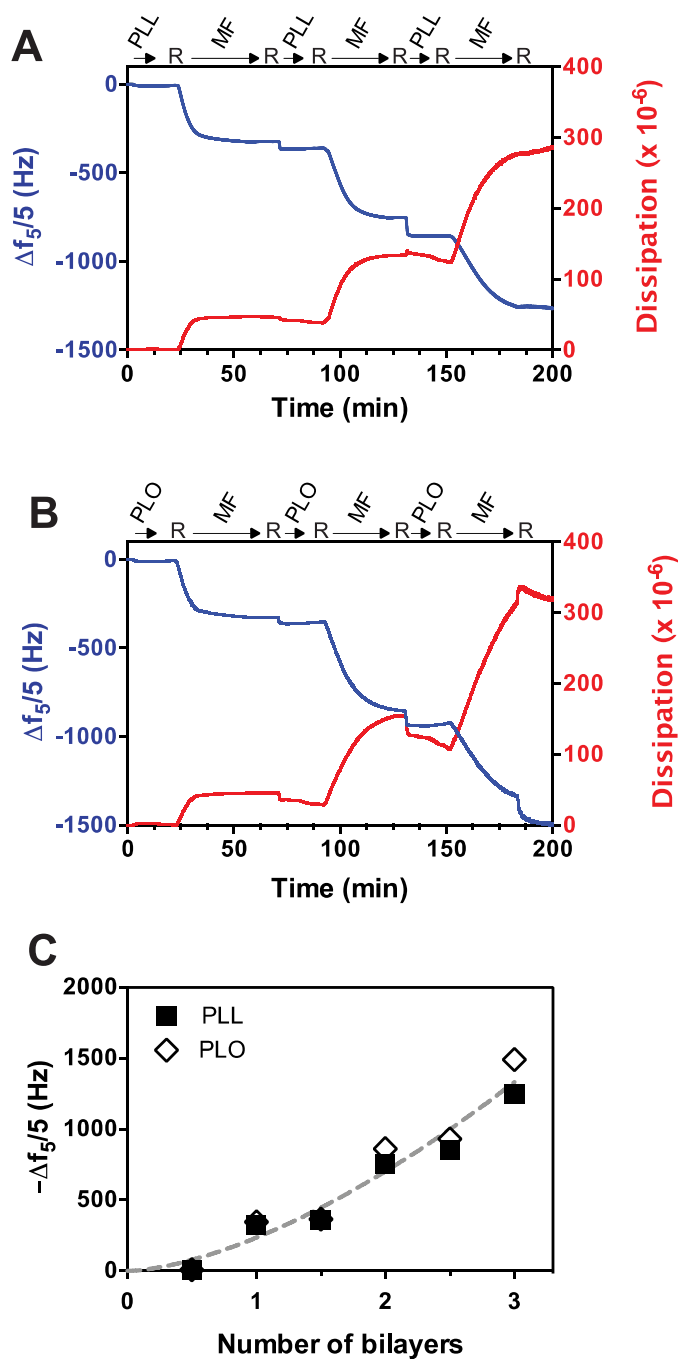

Figure 6. QCM-D measurements showing frequency changes in the 5 th overtone and the corresponding dissipation changes during the build-up of (A) (PLL/MF) ${ }_{n}$ and (B) (PLO/MF) ${ }_{n}$ multilayers in PBS ("R" indicates the rinsing step with PBS). (C) Evolution of the frequency shift, taken at the 5th overtone, as a function of the number of bilayers, $n$, upon the build-up of (PLL/MF $)_{n}$ and (B) $(\mathrm{PLO} / \mathrm{MF})_{n}$ (as indicated).

shown that the addition of the polycation did not induce any noticeable decrease of the dissipation, suggesting that no contraction of the film occurred during the multilayer's construction. The evolution of $\Delta f$ as a function of the number of bilayers provides a more direct evidence regarding the construction of PLL/MF and PLO/MF multilayers, indicating that the LbL self-assembly did not change whether PLL or $\mathrm{PLO}$ was used as a polycation (Figure 6C). It is worth noting that upon the build-up of 4 bilayers, the response of the sensor could no longer be monitored in an efficient way at all of the overtones. This is probably because the film became too thick and extensively hydrated. The above observations are thus a direct proof of the involvement of MF as a polyanion for $\mathrm{LbL}$ assembly in the chosen conditions.

AFM images revealed a clear evolution of the surface morphology as a result of the LbL self-assembly of (PLL/MF) multilayers with $n=1,3$, and 5 bilayers (Figure 7). After the deposition of 1 bilayer, the surface showed the presence of isolated particles attributable to MF (Figure 7A), similarly to those observed on the glass surface (Figure 3A,D). The typical cross section revealed that particles were not homogeneous in size; many of them were below a height of $5 \mathrm{~nm}$, and some reached $30 \mathrm{~nm}$. After the deposition of 3 bilayers, the density of particles and their size clearly increased, a great proportion of particles exceeding a height of $100 \mathrm{~nm}$ (Figure 7B). However, in this situation, AFM images showed a packing of particles in close contact with each other. Accordingly, the real particle height could not be evaluated reliably because the tip was too large to penetrate into the interstices between particles (cross section in Figure $7 \mathrm{~B}$ ). The surface roughness, $R_{\mathrm{rms}}$ (computed from $10 \mu \mathrm{m} \times 10 \mu \mathrm{m}$ AFM height images), strikingly increased from $6 \pm 0.8$ to $44 \pm 3.1 \mathrm{~nm}$ when the number of deposited bilayers $n$ increased from 1 to 3 . The surface roughness also increased after the deposition of 5 bilayers $\left(R_{\mathrm{rms}}=61 \pm 3.7 \mathrm{~nm}\right)$ due to the presence of larger particle aggregates (Figure $7 \mathrm{C}$ ).

2.4. Catalytic Properties of (PLL/MF $)_{n}$ Multilayers. The catalytic properties of MF embedded in the multilayered film showed that CYP maintained a significant activity in the adsorbed state, independently of the number of bilayers $(n=1$, 3 , or 5). Typical evolution of the resorufin production as a function of time is given in Figure 8A, showing a profile similar to that obtained with free MF in solution (Figure 5B). A linear portion is clearly observed up to about $30 \mathrm{~min}$, corresponding to the initial activity, and a plateau is reached after about 50 min (Figure 8A). Importantly, in situations with practical relevance (e.g., screening tests in bioreactors), the ability of embedded MF to remain active after repeated uses is the main standard. This is what is called the operational stability. In the present study, three successive use cycles were carried out on each sample during $30 \mathrm{~min}$ at $37^{\circ} \mathrm{C}$ and with intervals of $1 \mathrm{~h}$. The period of $30 \mathrm{~min}$ of activity was chosen based on the trend observed in Figure 8A, to avoid the autoinactivation of enzymes. Results showed that a significant decrease of the catalytic activity occurred upon repeated uses, independently of the number of bilayers $n$ (Figure 8B). After 1 use, the (PLL/ $\mathrm{MF})_{1}$ sample showed the most extensive deactivation (residual activity $\sim 10 \%$ of the initial value), followed by the (PLL/MF) sample (residual activity $\sim 16 \%$ of the initial value). Interestingly, the activity was more preserved upon successive uses with increasing the number of bilayers (residual activity $\sim 85 \%$ of the initial value after 1 use for the (PLL/MF) sample). These results indicate that the operational stability is enhanced when increasing $-\Delta f$ (Figure S5, Supporting Information), which is reflecting the adsorbed amount of MF. It seems that the loss of activity upon successive uses was not due to a possible desorption of MF. Indeed, the supernatant did not show any significant activity (not shown).

These observations clearly show that MF may be immobilized through the sequential LbL assembly while preserving their catalytic properties. Increasing the number of bilayers, $n$, leads to an extensive aggregation of MF, which seems to be mediated by the presence of the polycation, as depicted in Figure 9. It appears that the increase of the amount of adsorbed MF, resulting in their extensive aggregation, leads to a better preservation of their operational stability. The formation of aggregates may insure a better proximity of CYP and CPR enzymes. Thus, evidencing this mechanism would be an original result, and the question clearly deserves further investigation. 

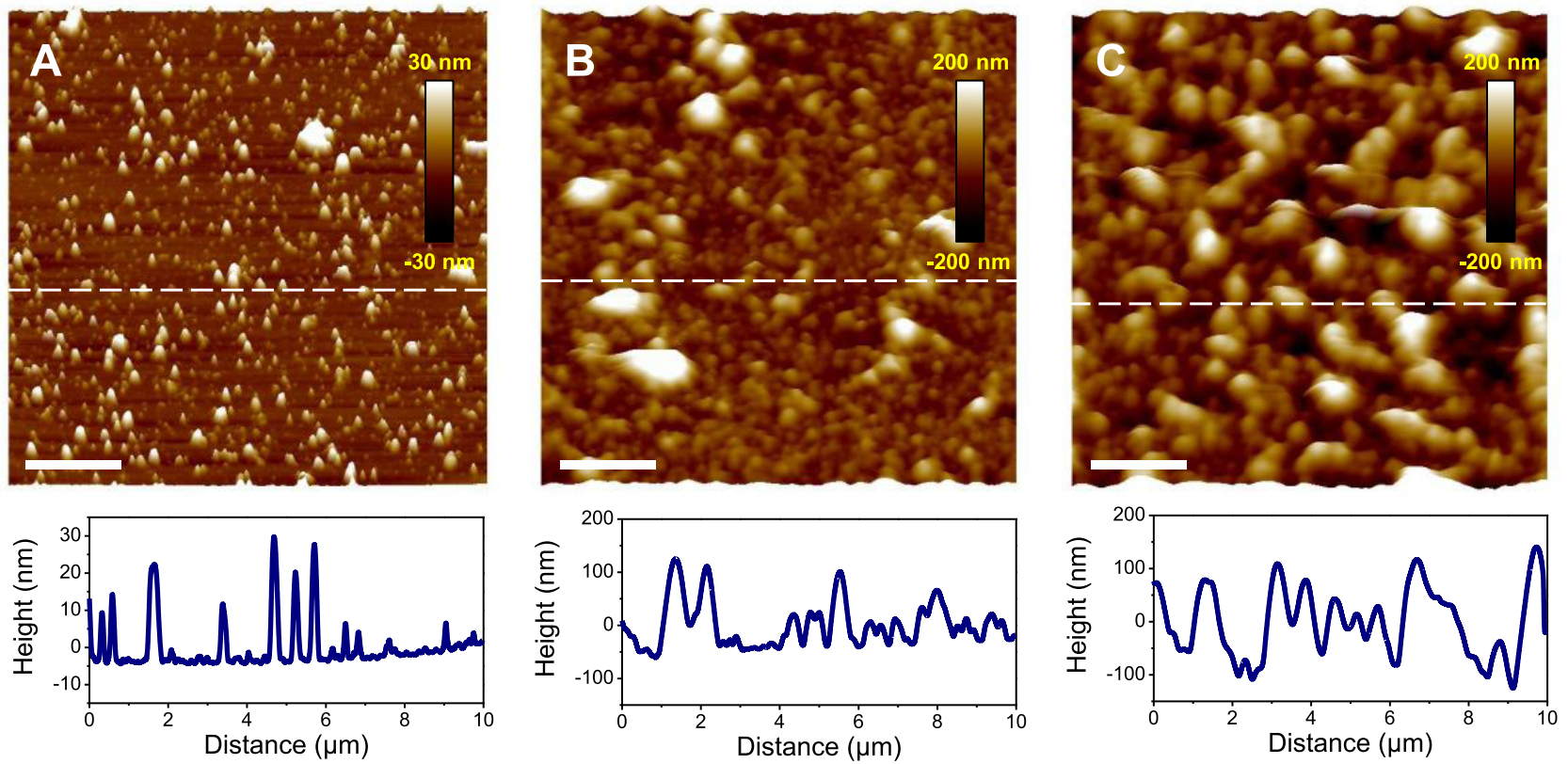

Figure 7. Representative AFM height images recorded in PBS buffer solution after deposition of (PLL/MF $)_{n}$ multilayers: $(\mathrm{A}) n=1$; $(\mathrm{B}) n=3$, and (C) $n=5$. Cross sections were taken at the location indicated by the white broken lines on the images (scale bars $=2 \mu \mathrm{m}$ ).
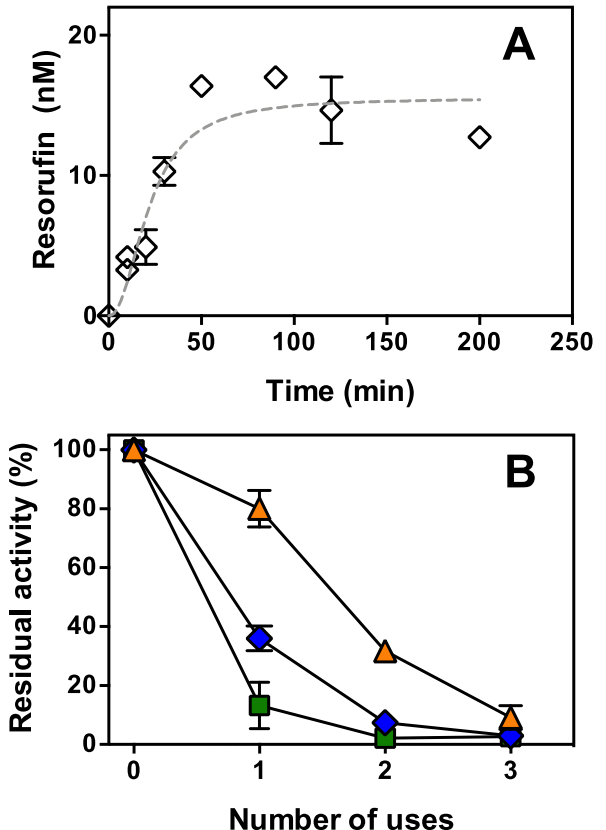

Figure 8. (A) Measurement of the kinetic activity of CYP using the EROD essay on (PLL/MF) ${ }_{3}$ multilayers. The dashed line is only guide for the eye. (B) Operational stability of (PLL/MF) ${ }_{n}$ multilayers (residual activity expressed in percentage of the initial enzymatic activity): $n=1$ (green solid box); $n=3$ (blue tilted square, solid); and $n=5$ (orange triangle up, solid); error bars correspond to the standard deviations of three independent experiments.

\section{CONCLUSIONS}

The successful design of multilayered films incorporating nanosized bacterial membrane fractions (MF), which overexpress cytochrome $\mathrm{P} 450$ (CYP) and cytochrome P450 reductase (CPR), was reported. In solution, MF exhibited a large particle size distribution with a mean hydrodynamic
A
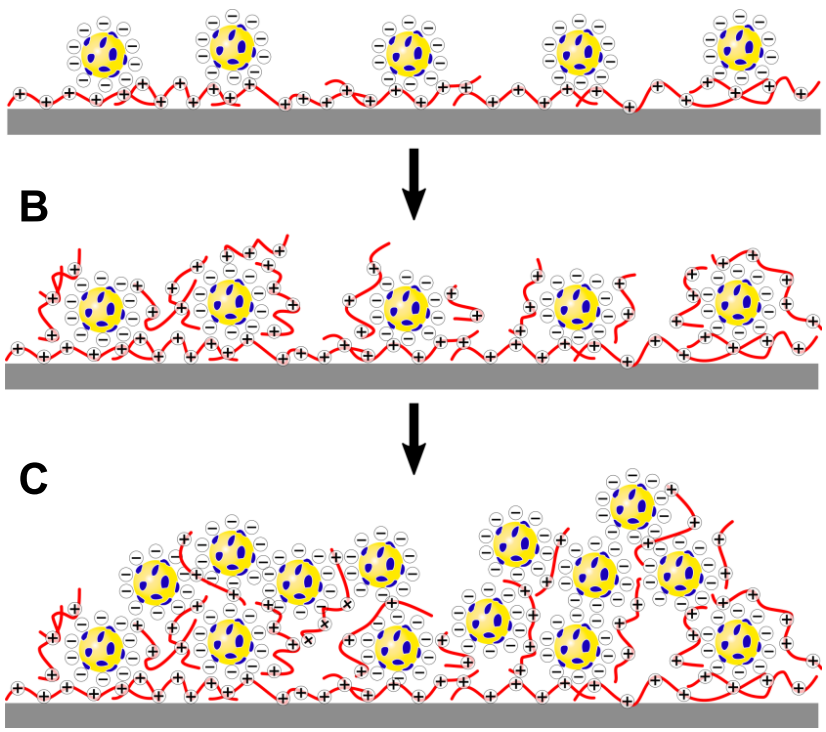

Figure 9. Sketch depicting the sequential layer-by-layer assembly of positively charged polyelectrolyte (PLL) and negatively charged MF and showing the (A) adsorption of 1 bilayer followed by (B) adsorption of the polycation and (C) the subsequent adsorption of MF. For the sake of clarity, MF are represented as monodisperse spheroid-shaped particles.

diameter around $200 \mathrm{~nm}$. Time-resolved DLS measurements showed that the aggregation of MF did not occur independently of their concentration in solution. Once adsorbed on the solid surface, MF mostly adopted a flattened conformation with a low tendency to aggregate. In situ QCM$\mathrm{D}$ monitoring revealed the ability of MF to be incorporated in a sequential LbL assembly using PLL or PLO as a polycation. In this case, MF showed an extensive tendency to aggregate 
within the multilayered films that became more noticeable when increasing the number of bilayers.

Enzyme assays revealed that MF preserved their CYP1A2 catalytic properties in the multilayered films. More importantly, it was shown that the ability of embedded MF to remain active after repeated uses, i.e., operational stability, increased markedly with increasing the number of bilayers. This behavior may be associated with the enhancement of MF aggregation leading to a better preservation of their enzymatic activities.

The strategy described in this article provides a practical way for the immobilization of enzymes from CYP family while preserving their catalytic properties. Indeed, owing to the versatility of $\mathrm{LbL}$ assembly, the incorporation of $\mathrm{MF}$ overexpressing CYP and CPR in multilayered films may easily include various enzymes from the CYP family. This is particularly important for the design of biomimetic bioreactor to assess xenobiotic metabolism with the aim to provide a reliable evaluation of the potential toxic effects due to xenobiotic absorption.

\section{EXPERIMENTAL SECTION}

4.1. Membrane Fractions (MF) and Polyelectrolytes. Poly-L-lysine (PLL, $M_{\mathrm{w}} 30-70 \mathrm{kDa}$ ) and poly-L-ornithine (PLO, $M_{\mathrm{w}} 30-70 \mathrm{kDa}$ ) were purchased from Sigma-Aldrich (France). Polyelectrolyte solutions were prepared in Dulbecco's phosphate buffer saline (PBS, pH 7.4, Thermo-Fisher, France) at a concentration of $1 \mathrm{mg} / \mathrm{mL}$. Membrane fractions (MF) overexpressing a human recombinant cytochrome P450 (CYP) were obtained from Cypex (England). CYP1A2 was individually coexpressed with human $\mathrm{NADPH}-$ cytochrome P450 reductase in E. coli following the procedure described elsewhere. ${ }^{44}$ Then, a cell fractionation method was used to allow the purification of membrane fractions with highly enriched recombinant enzymes. MF were provided in a storage buffer (50 mM Tris-acetate, $\mathrm{pH} 7.6 ; 250 \mathrm{mM}$ sucrose; 0.25 $\mathrm{mM}$ ethylenediaminetetraacetic acid) at an estimated CYP concentration of $1 \mathrm{mM}$ and a total protein concentration of 10 $\mathrm{mg} / \mathrm{mL}$. Stock solutions were stored at $-80{ }^{\circ} \mathrm{C}$. MF were diluted in PBS at $\mathrm{pH} 7.4$ for the different experiments and used immediately. All MF concentrations are given in estimated CYP concentration.

4.2. Layer-by-Layer Assembly. The substrates used were disks of cover glasses (of $10 \mathrm{~mm}$ diameter, VWR, France), cleaned prior to use in a piranha solution: $\mathrm{H}_{2} \mathrm{SO}_{4}(98 \%) / \mathrm{H}_{2} \mathrm{O}_{2}$ (27\%) $1: 1 \mathrm{v} / \mathrm{v}$. (Caution! piranha solutions react violently with organic materials and should not be stored in closed containers). The build-up of the (PLL/MF) ${ }_{n}$ and (PLO/ $\mathrm{MF})_{n}$ multilayer films was performed as follows: without the adsorption of an anchoring layer, the substrate was alternately immersed in PLL, or PLO, and MF solutions. The dipping time was fixed at $15 \mathrm{~min}$ for polyelectrolyte solutions and 30 min for MF. After each dipping step, the samples were rinsed in three different baths ( 2 min each) of the buffer solution used for LbL assembly.

4.3. DLS. Dynamic light scattering (DLS) measurements were performed using a commercial instrument (Malvern Zetasizer Nano ZS, Malvern Instruments Ltd, U.K.) equipped with a $\mathrm{He}-\mathrm{Ne}$ laser at $633 \mathrm{~nm}$. Experiments were performed in the static mode on MF dilution ( $20 \mathrm{nM}, \mathrm{PBS}$ ) at $22{ }^{\circ} \mathrm{C}$ in a polystyrene cuvette. In this mode, the device monitors the fluctuation of the intensity of scattered light from the particles at $90^{\circ}$ angle. The raw data were processed using Zetasizer software that gives access to a size distribution histogram and average hydrodynamic diameter $\left(d_{\mathrm{H}}\right)$. The value of $d_{\mathrm{H}}$ was obtained from the Stokes-Einstein equation

$$
d_{\mathrm{H}}=\frac{k_{\mathrm{B}} T}{3 \pi \eta D}
$$

where $k_{\mathrm{B}}$ is Boltzmann's constant, $T$ is the absolute temperature $(\mathrm{K}), \eta$ is the solution viscosity $(\mathrm{mPa} s)$, and $D$ is the diffusion coefficient of the objects $\left(\mathrm{m}^{2} / \mathrm{s}\right)$. The results are presented as the mean and standard deviation of five replicates.

4.4. EPM. Electrophoretic mobility (EPM) measurements were carried out using Malvern Zetasizer nano ZS with disposable polystyrene cuvettes (DTS1061, Malvern Instruments Ltd, U.K.) in PBS at $22{ }^{\circ} \mathrm{C}$. The performance of the instrument was systematically verified (every six samples) using a $\zeta$-potential standard solution (Malvern, DTS1232). $\zeta$ potential was calculated using the Henry law and the Smoluchowski approximation

$$
\mu=\frac{2 \varepsilon \varepsilon_{0} \zeta}{3 \eta} f(\kappa a)
$$

where $\mu$ is the electrophoretic mobility, $a$ is the particle radius, and $\varepsilon$ is the dielectric permittivity. $f(\kappa a)$ is Henry's function, which depends on the thickness of the double layer, $\kappa^{-1}$, that acts to screen the electrostatic interactions around the particle. According to the Smoluchowski approximation, for thin double layer, i.e., $\kappa a \gg 1, f(\kappa a) \rightarrow 3 / 2$. The results are presented as the mean and standard deviation of five replicates.

4.5. IR Analyses. Attenuated total reflection infrared (ATR-IR) analyses were performed on solutions of MF prepared in PBS buffer at a concentration of $20 \mathrm{nM}$. One milliliter of solution was deposited on the ATR ZnSe crystal, and spectra were obtained by the sum of 256 scans at $8 \mathrm{~cm}^{-1}$ resolution using a pure solution of $\mathrm{PBS}$ as a reference. All analyses were performed at room temperature using a Nicolet 5700 Fourier transform infrared spectrometer equipped with a liquid nitrogen-cooled MCT detector.

4.6. AFM. AFM images were recorded using a commercial AFM (Nanoscope VIII MultiMode AFM, Bruker Nano Inc., Nano Surfaces Division, Santa Barbara, CA) equipped with a $150 \mu \mathrm{m} \times 150 \mu \mathrm{m} \times 5 \mu \mathrm{m}$ scanner (J-scanner). The glass substrates were fixed on a steel sample puck using a small piece of adhesive tape. Images were recorded in PBS buffer at room temperature $\left(\sim 22{ }^{\circ} \mathrm{C}\right)$ using the peak force tapping mode. ${ }^{57}$ For this purpose, a quartz fluid cell was used. The mounted samples were immediately transferred into the AFM liquid cell while avoiding dewetting. Oxide-sharpened microfabricated $\mathrm{Si}_{3} \mathrm{~N}_{4}$ cantilevers were used (SNL-10, Bruker Nano Inc., Nano Surfaces Division, Santa Barbara, CA). The spring constants of the cantilevers were measured using the thermal noise method, yielding values around $0.2 \mathrm{~N} / \mathrm{m}$. The curvature radius of silicon nitride tips was about $12 \mathrm{~nm}$ (manufacturer specifications). The deflection sensitivity was calibrated by recording the response of the cantilever on a bare glass substrate (cleaned as described above), considered as an infinitely stiff surface. All topographic images shown in this article were flattened using a third-order polynomial to correct surface tilt and eliminate bow effects.

4.7. QCM-D. The build-up of the multilayered film containing MF was monitored in situ by quartz crystal microbalance with dissipation monitoring. Measurements were performed with a Q-Sense E4 system (Biolin Scientific, 
Sweden) at a temperature of $22.0 \pm 0.1{ }^{\circ} \mathrm{C}$. The crystal used was a thin AT-cut quartz coated with a thin $\mathrm{SiO}_{2}$ film (thickness $\sim 50 \mathrm{~nm}$ ) provided by Q-Sense. It was used after a classical cleaning with an anionic detergent (SDS) and a subsequent UV-ozone treatment. Oscillations of the crystal at the resonant frequency $(5 \mathrm{MHz})$ or at one of its overtones $(15$, $25,35,45,55,65 \mathrm{MHz}$ ) were obtained when applying ac voltage. The variations of the resonance frequency $(\Delta f)$ and of dissipation $(D)$ were monitored upon adsorption. Solutions were injected into the measurement cell using a peristaltic pump (Ismatec IPC-N 4) at a flow rate of $30 \mu \mathrm{L} / \mathrm{min}$. Prior to the multilayer build-up, PBS solution was injected to establish the baseline. The construction of $(\mathrm{PLL} / \mathrm{MF})_{n}$ or $(\mathrm{PLO} / \mathrm{MF})_{n}$ multilayers was performed as follows: first, PLL, or PLO, solution $(1 \mathrm{mg} / \mathrm{mL}, \mathrm{PBS})$ was brought into the measurement cell over $15 \mathrm{~min}$. Subsequently, rinsing was performed for 10 min using PBS. A MF solution (20 nM, PBS) was then injected for $30 \mathrm{~min}$ following by a rinsing step. This procedure was repeated until the desired number of bilayers was reached.

4.8. Enzyme Assay. The catalytic activity of MF was evaluated by determining the CYP1A2 activity following the so-called ethoxyresorufin O-deethylase (EROD) protocol. The reaction consists in the oxidation of 7-ethoxyresorufin yielding resorufin and uses $\mathrm{NADPH}$ as a cofactor according to

$$
\begin{gathered}
\text { 7-ethoxyresorufin }+\mathrm{O}_{2}+\mathrm{NADPH}+\mathrm{H}^{+} \\
\rightarrow \text { resorufin }+\mathrm{H}_{2} \mathrm{O}+\mathrm{NADP}^{+}
\end{gathered}
$$

The resorufin concentration was determined by fluorescence measurements at the following wavelengths: $\lambda_{\mathrm{ex}}=560 \mathrm{~nm}$ and $\lambda_{\mathrm{em}}=590 \mathrm{~nm}$; the other reagents and products do not interfere at these wavelengths. A calibration curve was preliminarily established to relate the fluorescence at $590 \mathrm{~nm}$ to resorufin concentration. For free MF, solutions with different concentrations of MF were prepared by dilution from stock solution $(1 \mathrm{mM})$. Catalytic activity measurements were carried out in PBS at $37{ }^{\circ} \mathrm{C}$ in the presence of 7-ethoxyresorufin $(0.3 \mu \mathrm{M})$ and NADPH $(1 \mathrm{mM})$. For this purpose, $200 \mu \mathrm{L}$ of reagents (MF, 7-ethoxyresorufin, and $\mathrm{NADPH}$ ) was introduced in a Corning 96-well black plate (Fisher Scientific), which was placed in the fluorescence spectrometer (Fluostar Optima, BMG Labtech, Germany). The fluorescence was measured every $30 \mathrm{~s}$ during $90 \mathrm{~min}$. For immobilized MF, glass substrates coated with PLL/MF multilayers were incubated in a PBS solution containing 7-ethoxyresorufin and NADPH at the same concentrations indicated above. The fluorescence was measured after the desired incubation time is reached (see the Supporting Information for more details).

4.9. Operational Stability. The reusability of MF incorporated in the multilayered film was evaluated by measuring the residual activities periodically at intervals of $30 \mathrm{~min}$ over a period of $2 \mathrm{~h} 30$ at $37{ }^{\circ} \mathrm{C}$. Between two successive measurements, samples were rinsed three times with PBS and reused immediately while avoiding dewetting.

\section{ASSOCIATED CONTENT}

\section{S Supporting Information}

The Supporting Information is available free of charge on the ACS Publications website at DOI: 10.1021/acsomega.8b01738.

MF adsorption on solid surface, catalytic activity of MF in solution, and catalytic activity of immobilized MF (PDF)

\section{AUTHOR INFORMATION}

\section{Corresponding Author}

*E-mail: jessem.landoulsi@sorbonne-universite.fr.

ORCID

Jessem Landoulsi: 0000-0003-2394-4437

Notes

The authors declare no competing financial interest.

\section{REFERENCES}

(1) Rappaport, S. M. Implications of the Exposome for Exposure Science. J. Exposure Sci. Environ. Epidemiol. 2011, 21, 5-9.

(2) Ewald, B. H.; Gregg, D. A. Animal Research for Animals. Ann. N. Y. Acad. Sci. 1983, 406, 48-58.

(3) Gad, S. C. Animal Models in Toxicology, 2nd ed.; CRC/Taylor \& Francis: Boca Raton, 2007.

(4) Allen, D.; Waters, M. D. Reducing, Refining and Replacing the Use of Animals in Toxicity Testing, 2nd ed.; Royal Society of Chemistry, 2013.

(5) Shanks, N.; Greek, R.; Greek, J. Are Animal Models Predictive for Humans? Philos. Ethics Humanit. Med. 2009, 4, No. 2.

(6) Adler, S.; Basketter, D.; Creton, S.; Pelkonen, O.; van Benthem, J.; Zuang, V.; Andersen, K. E.; Angers-Loustau, A.; Aptula, A.; BalPrice, A.; et al. Alternative (Non-Animal) Methods for Cosmetics Testing: Current Status and Future Prospects-2010. Arch. Toxicol. 2011, 85, 367-485.

(7) Flecknell, P. Replacement, Reduction and Refinement. Altex 2002, 19, 73-78.

(8) Krishna, D. R.; Klotz, U. Extrahepatic Metabolism of Drugs in Humans. Clin. Pharmacokinet. 1994, 26, 144-160.

(9) Kirchmair, J.; Göller, A. H.; Lang, D.; Kunze, J.; Testa, B.; Wilson, I. D.; Glen, R. C.; Schneider, G. Predicting Drug Metabolism: Experiment and/or Computation? Nat. Rev. Drug Discovery 2015, 14, 387-404.

(10) Meunier, B.; de Visser, S. P.; Shaik, S. Mechanism of Oxidation Reactions Catalyzed by Cytochrome P450 Enzymes. Chem. Rev. 2004, 104, 3947-3980.

(11) Barnaba, C.; Gentry, K.; Sumangala, N.; Ramamoorthy, A. The Catalytic Function of Cytochrome P450 Is Entwined with Its Membrane-Bound Nature. F1000Research 2017, 6, No. 662.

(12) Barnaba, C.; Ramamoorthy, A. Picturing the MembraneAssisted Choreography of Cytochrome P450 with Lipid Nanodiscs. ChemPhysChem 2018, DOI: 10.1002/cphc.201800444.

(13) Zhang, D.; Luo, G.; Ding, X.; Lu, C. Preclinical Experimental Models of Drug Metabolism and Disposition in Drug Discovery and Development. Acta Pharm. Sin. B 2012, 2, 549-561.

(14) Dürr, U. H. N.; Waskell, L.; Ramamoorthy, A. The Cytochromes P450 and B5 and Their Reductases-Promising Targets for Structural Studies by Advanced Solid-State NMR Spectroscopy. Biochim. Biophys. Acta, Biomembr. 2007, 1768, 32353259.

(15) Schneider, E.; Clark, D. S. Cytochrome P450 (CYP) Enzymes and the Development of CYP Biosensors. Biosens. Bioelectron. 2013 $39,1-13$.

(16) Aissaoui, N.; Bergaoui, L.; Boujday, S.; Lambert, J.-F.; Méthivier, C.; Landoulsi, J. Enzyme Immobilization on SilaneModified Surface through Short Linkers: Fate of Interfacial Phases and Impact on Catalytic Activity. Langmuir 2014, 30, 4066-4077.

(17) Aissaoui, N.; Bergaoui, L.; Landoulsi, J.; Lambert, J.-F.; Boujday, S. Silane Layers on Silicon Surfaces: Mechanism of Interaction, Stability, and Influence on Protein Adsorption. Langmuir 2012, 28, 656-665.

(18) Dekeyser, C. M.; Buron, C. C.; Derclaye, S. R.; Jonas, A. M.; Marchand-Brynaert, J.; Rouxhet, P. G. Degradation of Bare and Silanized Silicon Wafer Surfaces by Constituents of Biological Fluids. J. Colloid Interface Sci. 2012, 378, 77-82.

(19) Dekeyser, C. M.; Buron, C. C.; Mc Evoy, K.; Dupont-Gillain, C. C.; Marchand-Brynaert, J.; Jonas, A. M.; Rouxhet, P. G. 
Oligo(Ethylene Glycol) Monolayers by Silanization of Silicon Wafers: Real Nature and Stability. J. Colloid Interface Sci. 2008, 324, 118-126. (20) Blake, J. A.; Pritchard, M.; Ding, S.; Smith, G. C.; Burchell, B.; Wolf, C. R.; Friedberg, T. Coexpression of a Human P450 (CYP3A4) and P450 Reductase Generates a Highly Functional Monooxygenase System in Escherichia coli. FEBS Lett. 1996, 397, 210-214.

(21) Quehl, P.; Hollender, J.; Schüürmann, J.; Brossette, T.; Maas, R.; Jose, J. Co-Expression of Active Human Cytochrome P450 1A2 and Cytochrome P450 Reductase on the Cell Surface of Escherichia coli. Microb. Cell Fact. 2016, 15, No. 26.

(22) McGinnity, D. F.; Griffin, S. J.; Moody, G. C.; Voice, M.; Hanlon, S.; Friedberg, T.; Riley, R. J. Rapid Characterization of the Major Drug-Metabolizing Human Hepatic Cytochrome P-450 Enzymes Expressed in Escherichia coli. Drug Metab. Dispos. 1999, 27, 1017-1023.

(23) Moody, G. C.; Griffin, S. J.; Mather, A. N.; McGinnity, D. F.; Riley, R. J. Fully Automated Analysis of Activities Catalysed by the Major Human Liver Cytochrome P450 (CYP) Enzymes: Assessment of Human CYP Inhibition Potential. Xenobiotica 1999, 29, 53-75.

(24) Lavalle, P.; Voegel, J.-C.; Vautier, D.; Senger, B.; Schaaf, P.; Ball, V. Dynamic Aspects of Films Prepared by a Sequential Deposition of Species: Perspectives for Smart and Responsive Materials. Adv. Mater. 2011, 23, 1191-1221.

(25) Decher, G. Fuzzy Nanoassemblies: Toward Layered Polymeric Multicomposites. Science 1997, 277, 1232-1237.

(26) Bertrand, P.; Jonas, A.; Laschewsky, A.; Legras, R. Ultrathin Polymer Coatings by Complexation of Polyelectrolytes at Interfaces: Suitable Materials, Structure and Properties. Macromol. Rapid Commun. 2000, 21, 319-348.

(27) Farhat, T. R.; Schlenoff, J. B. Ion Transport and Equilibria in Polyelectrolyte Multilayers. Langmuir 2001, 17, 1184-1192.

(28) Ostrander, J. W.; Mamedov, A. A.; Kotov, N. A. Two Modes of Linear Layer-by-Layer Growth of Nanoparticle-Polyelectrolyte Multilayers and Different Interactions in the Layer-by-Layer Deposition. J. Am. Chem. Soc. 2001, 123, 1101-1110.

(29) Lojou, É.; Bianco, P. Buildup of Polyelectrolyte-Protein Multilayer Assemblies on Gold Electrodes. Role of the Hydrophobic Effect. Langmuir 2004, 20, 748-755.

(30) Markarian, M. Z.; Moussallem, M. D.; Jomaa, H. W.; Schlenoff, J. B. Hydrogen Bonding versus Ion Pairing in Polyelectrolyte Multilayers with Homopolynucleotides. Biomacromolecules 2007, 8, 59-64.

(31) Boudou, T.; Crouzier, T.; Ren, K.; Blin, G.; Picart, C. Multiple Functionalities of Polyelectrolyte Multilayer Films: New Biomedical Applications. Adv. Mater. 2010, 22, 441-467.

(32) Richardson, J. J.; Cui, J.; Björnmalm, M.; Braunger, J. A.; Ejima, H.; Caruso, F. Innovation in Layer-by-Layer Assembly. Chem. Rev. 2016, 116, 14828-14867.

(33) Onda, M.; Lvov, Y.; Ariga, K.; Kunitake, T. Sequential Actions of Glucose Oxidase and Peroxidase in Molecular Films Assembled by Layer-by-Layer Alternate Adsorption. Biotechnol. Bioeng. 1996, 51, $163-167$.

(34) Calvo, E. J.; Etchenique, R.; Pietrasanta, L.; Wolosiuk, A.; Danilowicz, C. Layer-By-Layer Self-Assembly of Glucose Oxidase and Os(Bpy)2ClPyCH2NH-poly(Allylamine) Bioelectrode. Anal. Chem. 2001, 73, 1161-1168.

(35) Shutava, T. G.; Kommireddy, D. S.; Lvov, Y. M. Layer-by-Layer Enzyme/Polyelectrolyte Films as a Functional Protective Barrier in Oxidizing Media. J. Am. Chem. Soc. 2006, 128, 9926-9934.

(36) Ma, H.; Hu, N.; Rusling, J. F. Electroactive Myoglobin Films Grown Layer-by-Layer with Poly(Styrenesulfonate) on Pyrolytic Graphite Electrodes. Langmuir 2000, 16, 4969-4975.

(37) Michel, M.; Arntz, Y.; Fleith, G.; Toquant, J.; Haikel, Y.; Voegel, J.-C.; Schaaf, P.; Ball, V. Layer-by-Layer Self-Assembled Polyelectrolyte Multilayers with Embedded Liposomes: Immobilized Submicronic Reactors for Mineralization. Langmuir 2006, 22, 23582364.

(38) vander Straeten, A.; Bratek-Skicki, A.; Germain, L.; D’Haese, C.; Eloy, P.; Fustin, C.-A.; Dupont-Gillain, C. Protein-Polyelectrolyte
Complexes to Improve the Biological Activity of Proteins in Layer-byLayer Assemblies. Nanoscale 2017, 9, 17186-17192.

(39) Biointerface Characterization by Advanced IR Spectroscopy, 1st ed.; Pradier, C.-M., Chabal, Y. J., Eds.; Elsevier, 2011.

(40) Parikh, S. J.; Chorover, J. Infrared Spectroscopy Studies of Cation Effects on Lipopolysaccharides in Aqueous Solution. Colloids Surf., B 2007, 55, 241-250.

(41) Quilès, F.; Humbert, F.; Delille, A. Analysis of Changes in Attenuated Total Reflection FTIR Fingerprints of Pseudomonas Fluorescens from Planktonic State to Nascent Biofilm State. Spectrochim. Acta, Part A 2010, 75, 610-616.

(42) Sohlenkamp, C.; Geiger, O. Bacterial Membrane Lipids: Diversity in Structures and Pathways. FEMS Microbiol. Rev. 2016, 40, 133-159.

(43) Raetz, C. R.; Dowhan, W. Biosynthesis and Function of Phospholipids in Escherichia coli. J. Biol. Chem. 1990, 265, 12351238.

(44) Pritchard, M. P.; Glancey, M. J.; Blake, J. A.; Gilham, D. E.; Burchell, B.; Wolf, C. R.; Friedberg, T. Functional Co-Expression of CYP2D6 and Human NADPH-Cytochrome P450 Reductase in Escherichia coli. Pharmacogenetics 1998, 8, 33-42.

(45) Jackman, J. A.; Choi, J.-H.; Zhdanov, V. P.; Cho, N.-J. Influence of Osmotic Pressure on Adhesion of Lipid Vesicles to Solid Supports. Langmuir 2013, 29, 11375-11384.

(46) Jackman, J. A.; Špačková, B.; Linardy, E.; Kim, M. C.; Yoon, B. K.; Homola, J.; Cho, N.-J. Nanoplasmonic Ruler to Measure Lipid Vesicle Deformation. Chem. Commun. 2015, 52, 76-79.

(47) Jackman, J. A.; Zhdanov, V. P.; Cho, N.-J. Nanoplasmonic Biosensing for Soft Matter Adsorption: Kinetics of Lipid Vesicle Attachment and Shape Deformation. Langmuir 2014, 30, 9494-9503.

(48) Gillissen, J. J. J.; Jackman, J. A.; Tabaei, S. R.; Yoon, B. K.; Cho, N.-J. Quartz Crystal Microbalance Model for Quantitatively Probing the Deformation of Adsorbed Particles at Low Surface Coverage. Anal. Chem. 2017, 89, 11711-11718.

(49) Marx, K. A. Quartz Crystal Microbalance: A Useful Tool for Studying Thin Polymer Films and Complex Biomolecular Systems at the Solution-Surface Interface. Biomacromolecules 2003, 4, 10991120.

(50) Reviakine, I.; Johannsmann, D.; Richter, R. P. Hearing What You Cannot See and Visualizing What You Hear: Interpreting Quartz Crystal Microbalance Data from Solvated Interfaces. Anal. Chem. 2011, 83, 8838-8848.

(51) Edvardsson, M.; Svedhem, S.; Wang, G.; Richter, R.; Rodahl, M.; Kasemo, B. QCM-D and Reflectometry Instrument: Applications to Supported Lipid Structures and Their Biomolecular Interactions. Anal. Chem. 2009, 81, 349-361.

(52) Ferhan, A. R.; Jackman, J. A.; Cho, N.-J. Investigating How Vesicle Size Influences Vesicle Adsorption on Titanium Oxide: A Competition between Steric Packing and Shape Deformation. Phys. Chem. Chem. Phys. 2017, 19, 2131-2139.

(53) Richter, R.; Mukhopadhyay, A.; Brisson, A. Pathways of Lipid Vesicle Deposition on Solid Surfaces: A Combined QCM-D and AFM Study. Biophys. J. 2003, 85, 3035-3047.

(54) Reimhult, E.; Höök, F.; Kasemo, B. Vesicle Adsorption on $\mathrm{SiO} 2$ and TiO2: Dependence on Vesicle Size. J. Chem. Phys. 2002, 117, 7401-7404.

(55) Ananth, A.; Genua, M.; Aissaoui, N.; Díaz, L.; Eisele, N. B.; Frey, S.; Dekker, C.; Richter, R. P.; Görlich, D. Reversible Immobilization of Proteins in Sensors and Solid-State Nanopores. Small 2018, 14, No. 1703357.

(56) Eisele, N. B.; Andersson, F. I.; Frey, S.; Richter, R. P. Viscoelasticity of Thin Biomolecular Films: A Case Study on Nucleoporin Phenylalanine-Glycine Repeats Grafted to a HistidineTag Capturing QCM-D Sensor. Biomacromolecules 2012, 13, 23222332.

(57) Landoulsi, J.; Dupres, V. Direct AFM Force Mapping of Surface Nanoscale Organization and Protein Adsorption on an Aluminum Substrate. Phys. Chem. Chem. Phys. 2013, 15, 8429-8440. 